\title{
O trabalho docente na educação infantil pública em Belo Horizonte
}

\author{
MÉRCIA DE FIGUEIREDO NORONHA PINTO \\ Universidade Federal de Minas Gerais \\ ADRIANA MARIA CANCELLA DUARTE \\ Universidade Federal de Minas Gerais \\ LIVIA MARIA FRAGA VIEIRA \\ Universidade Federal de Minas Gerais
}

Estudos recentes (Campos, 1994; Cerisara, 2002; Dalben et al., 2002; Rosemberg, 2001; Silva, 2003; Vieira, 1998; entre outros) têm demonstrado que o direito à educação infantil relaciona-se intimamente com o trabalho docente, especialmente no que tange às relações e condições de trabalho das profissionais que atuam com crianças. No âmbito dessa temática, buscou-se compreender e analisar as condições em que se realiza o trabalho docente nas Unidades Municipais de Educação Infantil (UMEIs) e nas escolas, no contexto de mudanças na política pública de educação infantil em Belo Horizonte, a partir da criação do cargo de educador infantil em 2003.

Naquele ano, o município implantou o Programa Primeira Escola, com a promulgação da lei n. 8.679/2003. Com base nessa lei, Belo Horizonte criou as UMEIs, deu início ao atendimento público a crianças de até 3 anos de idade e ampliou significativamente as vagas para crianças na faixa etária de 4 a 5 anos. Criou também o cargo de educador infantil, por meio de concurso público, para o exercício da função docente nessa etapa da educação básica.

A expansão da educação infantil em Belo Horizonte, até 2003, deu-se principalmente por meio de convênio entre a prefeitura e as creches comunitárias. $\mathrm{Na}$ rede pública municipal, até esse período, a oferta permaneceu apenas para as crianças de 4 a 6 anos. De acordo com dados repassados pela Secretaria Municipal de Educação (SMED) em 2008, no ano de 2003, Belo Horizonte atendeu 3.439 
crianças nas escolas de educação infantil e 3.952 nas escolas de ensino fundamental com turmas de educação infantil, totalizando 7.391 crianças atendidas na rede pública municipal.

A inserção dessa criança na rede municipal acontecia por meio das seguintes modalidades de atendimento: nas escolas infantis, nas turmas que funcionavam em escolas de ensino fundamental, no Programa Adote um Pré, ${ }^{1}$ e ainda nas matrículas das crianças de 6 anos no $1^{\circ}$ ciclo do ensino fundamental. Em todas essas modalidades, atuavam professoras da Rede Municipal de Educação de Belo Horizonte (RME/BH).

A oferta da educação infantil pública se caracterizou pela instabilidade em razão das estratégias que foram utilizadas para a sua expansão, ou seja, aproveitamento de professoras excedentes ou em regime de dobra e uso de espaços ociosos nas escolas de ensino fundamental e médio.

Em Belo Horizonte, a educação infantil consistia em uma política desenvolvida no campo da assistência social, pouco inserida nas políticas educacionais do município. Segundo estudos de Dalben et al. (2002), essa política acompanhava as tendências históricas de expansão dessa etapa da educação no Brasil, ou seja, a localização, a idade, a renda, a cor e a escolaridade dos pais, principalmente das mães, colaboravam para melhores ou piores condições de acesso das crianças à primeira etapa da educação básica. Os estudos apontavam que as crianças brancas e pertencentes às famílias com renda mensal acima de cinco salários mínimos tinham mais possibilidades de frequentar a educação infantil. Em contrapartida, as oportunidades educacionais para as crianças negras eram aquelas de pior qualidade, ofertadas pelo sistema. As autoras verificaram ainda a desigualdade na distribuição da oferta de educação infantil no município, ou seja, as regiões mais pobres e com maior concentração de crianças de 0 a 6 anos apresentavam menores coberturas de atendimento (idem).

A partir de 1993, na primeira gestão democrático-popular² em Belo Horizonte, a educação infantil passou a fazer parte da agenda política do governo. Observa-se, após essa ocasião, a implantação de diferentes ações e projetos visando à ampliação do atendimento e à melhoria da qualidade dos serviços prestados às crianças pequenas.

1 O Programa Adote um Pré foi uma das estratégias utilizadas pela SMED para a ampliação de vagas na década de 1990. Esse programa cedia professoras da Rede Municipal de Educação de Belo Horizonte (RME/BH), exclusivamente em regime de dobra, para atuar em turmas de crianças de 5-6 anos nas creches comunitárias ou filantrópicas, conveniadas com a Prefeitura de Belo Horizonte (PBH).

2 O chamado projeto democrático-popular surgiu, segundo Dulci (1997), pela necessidade de as esquerdas estabelecerem uma aliança social para disputar o poder político no Brasil. Segundo esse autor, seria impossível promover as reformas estruturais que o país tanto necessitava sem constituir um bloco social mais amplo que a classe operária fabril e os trabalhadores rurais. Seria preciso integrar também as classes médias assalariadas, os pequenos e médios proprietários da cidade e do campo e os setores empresariais que tinham e têm contradições mais que episódicas com o modelo econômico excludente. 
No Governo Patrus Ananias - Frente BH Popular (1993-1996) -, houve o investimento nas creches conveniadas com a Prefeitura de Belo Horizonte (PBH), mas não se avançou na ampliação da oferta pública de educação infantil. Destacaram-se ações relativas à formação das educadoras de creches (curso supletivo e magistério), de supervisão das instituições conveniadas e elaboração de materiais pedagógicos.

Na gestão Célio de Castro (1997-2000), os desafios e ações em relação à educação infantil tornaram-se mais intensos em Belo Horizonte, principalmente com a promulgação da Lei de Diretrizes e Bases da Educação Nacional (LDB - lei n. 9.394 em 1996). Nesse período, foram realizadas várias ações que subsidiaram a ampliação do atendimento público à educação infantil no município, tendo em vista os estudos que constataram os limites da política de convênios e consequentemente a necessidade de investimentos em uma rede pública de cuidado e educação de crianças menores de 7 anos.

Destarte, com o objetivo de responder às exigências legais e ampliar a oferta de vagas na rede pública, em 2003, na administração do prefeito Fernando Pimentel (2003-2008), o município implantou o Programa Primeira Escola alterando significativamente a educação infantil em Belo Horizonte.

Atualmente, a educação infantil pública é ofertada em jornada parcial e integral nas UMEIs, em período parcial nas escolas municipais de ensino fundamental que permanecem com turmas de educação infantil, nas escolas municipais de educação infantil e em uma escola municipal de tempo integral. As informações mostram que, no ano de 2008, o município de Belo Horizonte mais que dobrou o número de crianças atendidas pela RME/BH (um total de 14.813), se comparados com os números de 2003.

Observa-se nas escolas a existência de profissionais ocupantes do cargo de educador infantil e de professor municipal exercendo a mesma função, com atribuições e formação semelhantes e carreiras e salários diferentes. Isso se explica porque, a partir da promulgação da lei n. 8.679/2003, as profissionais da carreira de educador infantil passaram a exercer a docência na educação infantil da RME/BH.Desse modo, ressalta-se que, nas UMEIs inauguradas em 2004, atuam como docentes apenas as educadoras infantis e, nas escolas, atuam as educadoras infantis e as professoras que desempenhavam essa função antes da publicação da referida lei. Por indução da política, só as ocupantes do cargo de educador infantil deverão atuar nessa etapa da educação básica na RME/BH.

As perguntas que orientaram esta pesquisa foram: 1) Como e em que condições as docentes da educação infantil pública em Belo Horizonte exercem sua atividade laborativa? e 2) Quais as implicações da criação da carreira de educador infantil sobre o trabalho docente? O desenvolvimento da pesquisa se deu por meio de análise documental e da pesquisa de campo em uma UMEI e em uma escola de educação infantil. Como instrumentos de coleta de dados, utilizaram-se o questionário, a observação, a entrevista semiestruturada e o grupo focal.

Buscou-se conhecer, de um lado, o perfil profissional e sociodemográfico das professoras e das educadoras que atuavam nessa etapa da educação básica e, de outro, as condições de trabalho que diziam respeito à carreira docente, como salário, jornada, atribuições, autonomia no exercício da profissão e as oportunidades de formação continuada. 
A expressão "condições de trabalho" é entendida aqui como "o conjunto de recursos que possibilita uma melhor realização do trabalho educativo" (Kuenzer; Caldas, 2007, p. 10). Envolve elementos concernentes às condições materiais, como os equipamentos e os recursos materiais e pedagógicos disponíveis, e à carreira docente, como a admissão, as atribuições, a jornada de trabalho, o salário, a formação continuada, enfim, o que diz respeito às relações de emprego (Duarte, 2008). As condições de trabalho referem-se, portanto, à forma como está organizado o processo de trabalho docente. ${ }^{3}$

A teoria marxista aponta três elementos constituintes do processo de trabalho: primeiro, o trabalho em si, ou seja, a atividade adequada a um fim; segundo, o objeto sobre o qual o trabalho é realizado; e terceiro, os meios, a matéria, os instrumentos que se aplicam ao trabalho (Marx, 1983). No campo da educação, Silva (2007) considera que o "objeto" de trabalho do professor é o aluno, e seus instrumentos são os conhecimentos e as habilidades adquiridas no seu processo formativo geral e específico. Afinal, se a ação pedagógica, educativa, formativa é dirigida ao aluno, esse é o "objeto" do ensino, da educação, da formação, cuja diretriz é levada a termo pelo professor.

A docência pode ser analisada como qualquer outro trabalho humano, o que, para Tardif e Lessard (2005), implica descrever e analisar as atividades materiais e simbólicas dos trabalhadores tais como elas são realizadas nos próprios locais de trabalho. Para esses autores, ao estudar a docência, é necessário conhecer os componentes do trabalho, ou melhor, as redes, as escolas, a organização, os sujeitos, os objetos, os objetivos, os processos, os conhecimentos e as tecnologias, os resultados.

A distinção entre os conceitos de organização do trabalho escolar e a organização escolar é apresentada por Oliveira (2002), apesar de a autora considerar a relação de interdependência entre eles. Para ela, essa definição é fundamental para a compreensão das relações de trabalho na escola. A organização do trabalho escolar diz respeito à divisão do trabalho na escola, isto é, como o trabalho do professor e o dos demais trabalhadores é organizado na instituição escolar.

Refere-se à forma como as atividades estão discriminadas, como os tempos estão divididos, a distribuição das tarefas e competências, as relações de hierarquia que refletem relações de poder, entre outras características inerentes à forma como o trabalho é organizado. (idem, p. 131)

Já a organização escolar equivale às condições em que o ensino está estruturado, desde as competências administrativas de cada órgão do poder público até os currículos, as metodologias e as avaliações adotados (idem).

3 O processo de trabalho é aqui entendido com base nos autores: Antunes (1999), Braverman (1987), Peduzzi e Schraiber (2006) e Santos (1989). 


\section{A ORGANIZAÇÃO E O PROCESSO DE TRABALHO DOCENTE NA EDUCAÇÃO INFANTIL, NA RME/BH}

\section{AS ATIVIDADES DAS PROFESSORAS E DAS EDUCADORAS}

De acordo com o trabalho prescrito na documentação legal, ${ }^{4}$ as professoras e as educadoras devem, entre outras atividades, organizar tempos e espaços que privilegiem o brincar como forma de expressão, pensamento e interação; assegurar momentos de higiene, alimentação e repouso, objetivando o cuidar e o educar das crianças. As atividades realizadas pelas docentes compreendem, além do cuidado e da educação das crianças, os horários de estudo que acontecem individualmente, com os pares ou com a coordenação pedagógica. Nesses momentos, são feitas reuniões para a elaboração do Projeto Político Pedagógico (PPP), o planejamento das atividades, a produção de projetos de ensino, registros de avaliação das crianças e atendimento aos pais e aos familiares. As professoras e as educadoras fazem parte também da gestão da escola, participando em instâncias de decisão como as assembleias e os colegiados. Ou seja, o trabalho realizado com as crianças é apenas uma parcela da atividade docente. Constata-se também uma diversidade de outras tarefas, variáveis em relação à duração e à frequência, que afetam a carga de trabalho ${ }^{5}$ das professoras e das educadoras. A síntese das atividades realizadas pelas docentes consta no Quadro1.

Quadro 1 - Atividades das educadoras e professoras da RME/BH pesquisadas

\begin{tabular}{|l|}
\hline \multicolumn{1}{|c|}{ Belo Horizonte - 2008} \\
\hline Atividades com as crianças \\
\hline $\begin{array}{l}\text { Brincadeiras, passeios, acolhida, adaptação, festas, jogos, higienização, alimentação, } \\
\text { repouso, socialização, histórias, registros, movimento, artes e literatura. }\end{array}$ \\
\hline Atividades para as crianças \\
\hline $\begin{array}{l}\text { Parcerias com universidades, centros de saúde, Conselho Tutelar etc., encontros com os pais } \\
\text { e a comunidade, preparação das atividades, elaboração do material, registros e avaliação. }\end{array}$ \\
\hline Atividades com ou para os colegas \\
\hline $\begin{array}{l}\text { Elaboração do PPP, troca de experiências, estudos, planejamento das atividades, } \\
\text { orientação aos estagiários de apoio à inclusão das crianças com deficiência. }\end{array}$ \\
\hline Atividades de formação e de desenvolvimento profissional \\
\hline $\begin{array}{l}\text { Formação em serviço (cursos e outros eventos proporcionados pela SMED e/ou pela escola), } \\
\text { formação pessoal (leitura etc.) e participação em associações profissionais (sindicato etc.). }\end{array}$ \\
\hline Atividades ligadas à gestão escolar \\
\hline Participação no colegiado e nas assembleias escolares. \\
\hline
\end{tabular}

Fonte: Dados da pesquisa.

Elaboração de Mércia de Figueiredo Noronha Pinto.

4 As atribuições do cargo de educador infantil constam na lei n. 7.235/1996, anexo II (Belo Horizonte, 1996), com as alterações promovidas pela lei n. 8.679/2003 (Belo Horizonte, 2003), e no documento Estruturação do trabalho escolar na RME/BH: a organização do trabalho coletivo por ciclos de formação (Belo Horizonte, 2006) e no Edital 2/2008, anexo II (Belo Horizonte, 2008).

5 A carga de trabalho dos docentes pode ser analisada, segundo Tardif e Lessard (2005), de um ponto de vista administrativo, definida em conteúdos e duração pela organização escolar em virtude das normas oficiais ou pelo ângulo das exigências reais do processo de trabalho cotidiano. As análises aqui efetuadas procuraram considerar a combinação dessas duas dimensões. 
Nesse sentido, entende-se que a docência, conforme propõe Souza (2008, p. 5), é uma profissão de tempo integral que ocupa não só o espaço público, como também o privado. $\mathrm{O}$ tempo da atividade produtiva remunerada está longe de ser impermeável ao tempo da vida privada (ação doméstica, lazer, descanso). A tarefa com as crianças pequenas requer para essas professoras e essas educadoras exigências específicas que afetam a carga de trabalho.

\section{CARREIRA E REMUNERAÇÃO DA EDUCADORA INFANTIL}

O cargo de educador infantil integra o quadro especial da SMED como classe de cargo de provimento efetivo do plano de carreira dos servidores da educação (art. 3', lei n. 8.679/2003).

$\mathrm{O}$ ingresso das educadoras infantis acontece por meio de concurso público de provas e títulos, obedecendo à determinação do art. 67 da LDB (lei n. 9.394/1996).

Os padrões de vencimento, a qualificação exigida e a jornada de trabalho foram estabelecidos pelo edital de concurso público para provimento do cargo de educador infantil no município de Belo Horizonte (anexo I, Edital 2, de 7 de março de 2008), conforme consta na Tabela 1.

Tabela 1 - Fragmento do anexo I - Edital 2/2008

\begin{tabular}{c|c|l|c|c}
\hline $\begin{array}{c}\text { Cargos/ } \\
\text { Especialidades }\end{array}$ & $\begin{array}{c}\text { Código } \\
\text { do Cargo }\end{array}$ & Habilitação Exigida & $\begin{array}{c}\text { Jornada de } \\
\text { Trabalho }\end{array}$ & $\begin{array}{c}\text { Vencimentos } \\
\text { Janeiro/2008 }\end{array}$ \\
\hline Educador infantil & 103 & $\begin{array}{l}\text { Curso de nível } \\
\text { médio completo na } \\
\text { modalidade normal }\end{array}$ & $\begin{array}{l}4,5 \mathrm{~h} \text { (quatro horas } \\
\text { e meia) diárias }\end{array}$ & $\mathrm{R} \$ 700,05$ \\
\hline
\end{tabular}

Fonte: Belo Horizonte (2008, s.p.).

Elaboração de Mércia de Figueiredo Noronha Pinto.

Não obstante a exigência da formação mínima para o cargo de educador, na ordem legal, ressalta-se que um número expressivo de educadoras em exercício na $\mathrm{RME} / \mathrm{BH}$ possui a formação superior, conforme disposto na Tabela 2.

Tabela 2 - Formação das educadoras infantis em exercício na RME/BH - 2008

\begin{tabular}{l|r}
\hline \multicolumn{1}{c|}{ Formação } & Número de Educadores Infantis \\
\hline Nível médio & 448 \\
Curso superior incompleto & 184 \\
Curso superior & 826 \\
Total & $\mathbf{1 . 4 5 8}$ \\
\hline
\end{tabular}

Fonte: PBH/ Secretaria Municipal de Educação/Gerência de Organização Escolar - out./2008. Elaboração de Mércia de Figueiredo Noronha Pinto.

Os dados na tabela mostram que, apesar de a habilitação exigida no concurso público para educador infantil ser o nível médio na modalidade normal, 826 educadoras infantis em exercício têm curso superior completo. Esse número refere-se a aproximadamente $60 \%$ do total (1.458). 
A carreira de educador infantil conta com 15 níveis, ocorrendo a progressão de escolaridade de dois níveis por formação em curso superior somente após a aquisição da estabilidade, ou seja, após o estágio probatório de três anos aliado à avaliação de desempenho. Cada nível da carreira corresponde a 5\% sobre o valor do vencimento, e constam ainda do plano de carreira os seguintes benefícios: quinquênio de $10 \%$ sobre o vencimento a cada cinco anos de efetivo exercício, e seis meses de licença-prêmio por assiduidade a cada dez anos de efetivo exercício.

Os níveis de vencimentos da classe de professor municipal (lei n. 7.235/1996) e de educador infantil (art. $6^{\circ}$, lei n. 8.679/2003) estão apresentados na Tabela 3.

Tabela 3 - Vencimentos das classes de professor e educador infantil na RME/BH, com vigência a partir de 1/11/2008

\begin{tabular}{rrrrrr}
\hline \multicolumn{5}{c}{ Vencimentos (R\$) } \\
\hline \multicolumn{5}{c}{ Professor } & \multicolumn{2}{c}{ Educador Infantil } \\
\hline Nível & Piso salarial & Nível & \multicolumn{1}{c}{ Piso salarial } \\
\hline $10^{*}$ & $1.473,76$ & 1 & 850,00 \\
11 & $1.547,45$ & 2 & 892,50 \\
12 & $1.624,82$ & 3 & 937,13 \\
13 & $1.706,06$ & 4 & 983,98 \\
14 & $1.791,37$ & 5 & $1.033,18$ \\
15 & $1.880,94$ & 6 & $1.084,84$ \\
16 & $1.974,98$ & 7 & $1.139,08$ \\
17 & $2.073,73$ & 8 & $1.196,04$ \\
18 & $2.177,42$ & 9 & $1.255,84$ \\
19 & $2.286,29$ & 10 & $1.318,63$ \\
20 & $2.400,60$ & 11 & $1.384,56$ \\
21 & $2.520,63$ & 12 & $1.453,79$ \\
22 & $2.646,66$ & 13 & $1.526,48$ \\
23 & $2.779,00$ & 14 & $1.602,80$ \\
24 & $2.917,95$ & 15 & $1.682,94$ \\
\hline
\end{tabular}

Nota: "A progressão na carreira por habilitação para professores de $1^{\circ}$ e $2^{\circ}$ ciclos é imediata em dez níveis.

Fonte: PBH/Secretaria Municipal Adjunta de Recursos Humanos/SMED/GEOE - out./2008. Elaboração de Mércia de Figueiredo Noronha Pinto.

Observa-se que o salário inicial das ocupantes do cargo de educador infantil equivale a pouco mais de $50 \%$ dos vencimentos do professor municipal. Entretanto, na prática, as atribuições da educadora infantil são semelhantes às das professoras que ainda atuam nessa etapa da educação básica nas escolas municipais.

\section{O TRABALHO DOCENTE NA EDUCAÇÃO INFANTIL, NA RME/BH}

\section{A JORNADA, AS ATRIBUIÇÕES E A INTENSIFICAÇÃO DO TRABALHO DOCENTE}

Em estudo sobre a duração da jornada de trabalho e seu grau de intensidade, Dal Rosso (2006) afirma que a intensificação refere-se ao desgaste dos indivíduos no processo de trabalho. De acordo com o autor, os ritmos, os tempos, as condições de 
trabalho e as exigências impostas aos trabalhadores/as agravam sua intensidade e indicam fortes consequências sobre a saúde desses, em seus aspectos físico, emocional e cognitivo.

A categoria intensificação do trabalho, na compreensão de Dal Rosso (idem) é reservada para descrever o fenômeno que reúne distintas formas e maneiras de fazer com que o trabalhador produza resultados quantitativa ou qualitativamente superiores, mantidas constantes as condições técnicas, a jornada e o número de trabalhadores.

Nesse sentido, para esse autor, uma nova onda de intensificação do trabalho, juntamente com o processo de reestruturação produtiva, disseminou-se pelo mundo a partir da década de 1980, considerando a racionalidade econômica do capitalismo atual, a realidade da precarização e das novas formas de trabalho e do desemprego. Os tempos de trabalho e não trabalho mesclam-se, e o trabalho tornou-se mais intenso.

Pode-se verificar a intensificação do trabalho docente como resultado da ampliação da jornada de trabalho e do aumento significativo de responsabilidades que os docentes tiveram com as reformas mais recentes na América Latina (Oliveira, 2006). Os professores podem assumir mais de uma jornada de trabalho, como observa essa autora, por necessidade de complementar a renda, em razão dos baixos salários do magistério em relação a outras ocupações de formação semelhante. Outra dimensão da intensificação do trabalho docente, segundo Oliveira (idem), é decorrente da extensão das horas e da carga de trabalho sem remuneração adicional, dentro da própria escola ou "levando trabalho para casa". A forma mais importante de intensificação do trabalho docente para ela é a que acontece na jornada de trabalho remunerada, uma vez que os docentes incorporam novas funções e responsabilidades ao seu trabalho, sendo forçados a dominarem novas práticas e saberes para responder às exigências do sistema e da comunidade, "caracterizando-se, portanto, em estratégias mais sutis e menos visíveis de exploração" (idem, p. 214).

$\mathrm{Na}$ educação infantil em Belo Horizonte, as atribuições docentes, para serem realizadas, ultrapassam em horas a jornada de trabalho remunerado. Do total de respondentes do questionário aplicado nesta pesquisa, $48 \%$ não conseguem realizar o seu trabalho dentro da carga horária diária prevista (4h30 min), conforme disposto na Tabela 4.

Tabela 4 - Número de profissionais da educação infantil da $\mathrm{RME} / \mathrm{BH}$ pesquisadas de acordo com a realização do trabalho dentro da carga horária diária prevista $(4 \mathrm{~h} 30 \mathrm{~min})$

\begin{tabular}{l|r|r}
\hline Realização do Trabalho & Frequência & \multicolumn{2}{|c}{ Percentual } \\
\hline Sim & 86 & $52 \%$ \\
Não & 80 & $48 \%$ \\
Total & $\mathbf{1 6 6}$ & $\mathbf{1 0 0 \%}$ \\
\hline
\end{tabular}

Fonte: Dados da pesquisa.

Elaboração de Mércia de Figueiredo Noronha Pinto.

Desse percentual, $74 \%$ frequentemente estendem a jornada por conta própria para realizar as atividades na escola, e $85 \%$ com frequência levam as atividades para realizar em casa. Para 52\% das professoras e das educadoras, o tempo necessário para a realização das tarefas na escola e em casa é de uma a duas horas diárias.

No grupo focal realizado nesta pesquisa, as professoras e as educadoras revelam a necessidade de realizar tarefas além das horas de trabalho pelas quais 
recebem os seus salários: "A gente leva um monte de coisa para cortar, para fazer em casa. Não dá para não levar" (Participante A). ${ }^{6}$

$\mathrm{O}$ fato de as atividades docentes extrapolarem o tempo cumprido na escola é questionado pela docente $\mathrm{N}$, que também participou do grupo focal: "Por que é que magistério tem que levar serviço para casa?”.

As professoras e as educadoras entrevistadas também apontam que a jornada de trabalho não se esgota na escola. A docente 7 relata que ela e as colegas que trabalham com as crianças de 5 anos sempre levam atividades para fazer em casa à noite ou nos fins de semana, porque o tempo destinado às horas de estudo é pouco e nem sempre são asseguradas as quatro horas semanais.

Os depoimentos também mostram a intensificação do trabalho docente, que acaba por acarretar em situações como a falta de tempo das professoras e das educadoras até mesmo para irem ao toalete. Essa intensificação do trabalho foi também verificada por Apple (1987) em seus estudos sobre o movimento de reformas educacionais nos EUA e seus impactos no trabalho docente. O relato da educadora que exerce a função de coordenadora pedagógica reflete a sobrecarga de tarefas e de responsabilidades na educação infantil:

Eu chego, geralmente, cinco para sete da manhã. [...] agora, nunca termina às $11 \mathrm{~h} 30 \mathrm{~min}$, que é nosso prazo de término, sempre a gente tem que ficar um pouquinho além da nossa carga horária. A gente não consegue dar conta de tudo porque a demanda é muito grande e a gente tem que estar sempre flexível. (Coordenadora pedagógica. Entrevista concedida a Mércia de Figueiredo Noronha Pinto. Belo Horizonte, 21 maio 2008)

O cansaço ao lidar com as crianças pequenas é outra questão que aponta para a intensificação do trabalho. Para as profissionais do berçário, o cansaço físico é assinalado como um aspecto de sobrecarga do trabalho por exigir, várias vezes ao dia, movimentos de se agachar, levantar, carregar as crianças no colo, para as trocas de fraldas e banhos.

Observa-se que as obrigações docentes têm sido mais numerosas. As novas demandas na relação com as crianças e com as atribuições referentes ao trabalho coletivo, à construção da proposta pedagógica, ao trabalho com a comunidade, às reuniões pedagógicas, entre outras, estão previstas nas legislações educacionais (LDB - lei n. 9.394/96; e resolução CME/BH n. 1/2000) e também na lei que instituiu o cargo de educador infantil, além de outras legislações. O excesso de atividades das professoras e das educadoras corrobora a intensificação do trabalho docente, característica das reformas educacionais.

6 As professoras e as educadoras que participaram da entrevista foram identificadas por números (de 1 a 15), de acordo com a ordem alfabética dos nomes, com exceção da educadora que está atuando como coordenadora pedagógica, que foi identificada pela função. As profissionais que participaram do grupo focal foram identificadas pela letra inicial do nome (A, C, K, D, R, V, F, M e S), e, no caso de uma delas, pela segunda letra do nome $(\mathrm{N})$, já que havia duas pessoas cujo nome iniciava com a mesma letra. 


\section{A PRECARIZAÇÃO DO TRABALHO DOCENTE E O SALÁRIO DA EDUCADORA INFANTIL}

A precarização do trabalho docente decorre da precarização do emprego presente na dinâmica atual da modernização do capital. As mudanças das últimas décadas na configuração do trabalho têm sido referidas como produtoras de novas formas de trabalho, que, segundo Castel (1998), se diferenciam em relação ao emprego assalariado protegido e por tempo indeterminado, característico do século XX, embora nem sempre hegemônico. A palavra de ordem é "flexibilizar". São várias as maneiras encontradas para escapar das amarras do emprego regulamentado, a saber: contratos temporários, por tempo parcial, por cooperativas; possibilidade de despedir empregados sem penalidades, de reduzir ou aumentar horário de trabalho, de pagar salários mais baixos, de mudar a jornada, de destinar atividades para empresas externas (Vasapollo, 2006).

Como o trabalho em geral, o trabalho docente tem sofrido relativa precarização das relações de emprego, apresentando uma tentativa de flexibilização e até mesmo de desregulamentação da legislação trabalhista, o que, segundo Oliveira (2006), pode ser verificado nos elementos referentes ao arrocho salarial, à ausência de piso salarial, à inadequação ou mesmo ausência de planos de cargos e salários, à perda de garantias trabalhistas e previdenciárias, à instabilidade do emprego no magistério público, a contratos temporários nas redes públicas de ensino.

O baixo salário é uma das questões mais visíveis da precarização do trabalho docente, e, segundo Sampaio e Marin (2004), é uma das principais queixas dos docentes. Essas autoras mostram ser o salário um fator que influi pesadamente sobre a precarização do trabalho dos professores, uma vez que, segundo elas, a "pauperização" da profissão significa a "pauperização" da vida pessoal, nas suas relações entre vida e trabalho.

$\mathrm{Na}$ educação infantil, a pesquisa realizada evidencia que a precarização do trabalho está na criação da carreira e no salário do educador infantil, diferenciados da carreira e do salário das professoras da $\mathrm{RME} / \mathrm{BH}$ que já exerciam a função docente nessa etapa da educação.

Em relação ao salário, o resultado obtido pelo questionário aplicado às educadoras e às professoras que participaram da pesquisa demonstra a insatisfação em relação a esse aspecto da carreira, conforme disposto na Tabela 5.

Tabela 5 - Avaliação de aspectos relativos à carreira: salário das profissionais da educação infantil da RME/BH pesquisadas - 2008

\begin{tabular}{l|r|r}
\hline \multicolumn{1}{c|}{ Avaliação } & Frequência & Percentual \\
\hline Ótimo & 0 & $0 \%$ \\
Bom & 12 & $7 \%$ \\
Regular & 50 & $30 \%$ \\
Ruim & 105 & $63 \%$ \\
Total & $\mathbf{1 6 7}$ & $\mathbf{1 0 0 \%}$ \\
\hline
\end{tabular}

Fonte: Dados da pesquisa.

Elaboração de Mércia de Figueiredo Noronha Pinto. 
De acordo com os dados da tabela, das 167 respondentes, 105 avaliam que o salário é ruim, e 50 que é regular; o que equivale a $93 \%$ do total. Apenas 12 profissionais consideram o salário bom, isto é, $7 \%$ do total. Nenhuma professora/ educadora avalia que o salário é ótimo.

Por meio das entrevistas realizadas com as educadoras, pode-se verificar que as declarações mais frequentes sobre o que as incomoda no trabalho estão relacionadas ao salário. Vejamos:

O que me incomoda? Bem, hoje, é... a desvalorização profissional do educador infantil. Hoje nós recebemos metade do valor que um professor de ensino fundamental recebe. Eu não entendo por que tem que haver essa diferença salarial. (Docente 5. Entrevista concedida a Mércia de Figueiredo Noronha Pinto. Belo Horizonte, 16 maio 2008)

Não estou satisfeita, não, pelo contrário, eu acho que eu estou revoltada com a situação e pode ser que eu venha a abrir mão dessa carreira devido a isso. Porque entre estar num lugar e não fazer porque não estou recebendo para merecer, eu prefiro abrir mão e procurar uma coisa melhor. (Docente 6. Entrevista concedida a Mércia de Figueiredo Noronha Pinto. Belo Horizonte, 27 maio 2008)

O que deixa a desejar é justamente o lado financeiro. É que nós não temos reconhecimento. Falta a remuneração mesmo. A gente ganha menos do que as professoras que fazem o mesmo trabalho de um educador e que ganham o dobro [...] Fico sempre pensando que eu quero estudar e procurar uma outra área que esteja mais valorizada. Porque realmente a gente tem desgaste, tem problema de saúde e, em contrapartida, não tem uma remuneração que vai te envolver. (Docente 1. Entrevista concedida a Mércia de Figueiredo Noronha Pinto. Belo Horizonte, 21 maio 2008)

As educadoras e as professoras também apontam a necessidade de elas terem outra ocupação para completar os rendimentos:

O salário nem é tão compensador. A gente tem que buscar outros recursos também, como eu tenho buscado. Faço bonecas, faço um monte de coisas. Tenho dobrado muitas vezes na escola e às vezes é cansativo. (Docente 5. Entrevista concedida a Mércia de Figueiredo Noronha Pinto. Belo Horizonte, 16 maio 2008)

O salário é uma das condições para a valorização dos profissionais da educação, conforme consta no texto da LDB n. 9.394/1996 (título VI), que recebeu expressiva atenção dos legisladores. Não obstante, segundo Oliveira (2008), não se verifica a efetivação na prática das garantias legais.

Para as entrevistadas, a desvalorização docente está relacionada com a etapa da educação na qual atuam.

Eu acho que é um profissional pouco valorizado, porque falta das pessoas, de um modo geral, a compreensão do que é realmente esse trabalho na educação 
infantil [...] o salário, ele é pior em relação às outras séries de ensino, por quê? Por que que é? Porque julgam que a gente não precisa ter um conhecimento, uma base teórica, de repente pode ser isso [...] a trancos e barrancos a gente está levando este compromisso, está concretizando este compromisso. Mas eu acho que falta ainda este reconhecimento deste profissional e especificamente dessa carreira que a prefeitura criou. Eu acho que a gente não é valorizada da forma que a gente deveria ser, não é vista a importância deste trabalho. (Docente 6. Entrevista concedida a Mércia de Figueiredo Noronha Pinto. Belo Horizonte, 27 maio 2008)

É interessante observar, nesse caso, que o salário e a valorização da profissão pressupõem o reconhecimento que a sociedade e a administração municipal atribuem ao trabalho docente na educação infantil, ou seja, a falta desse reconhecimento afeta particularmente as docentes.

Destarte, verifica-se que as profissionais são remuneradas de acordo com a carreira e a etapa da educação em que atuam e não em virtude da formação adquirida. Esse fato parece confirmar a constatação de Oliveira (2007), quando ela afirma que, no Brasil, a política salarial dos docentes apresenta grande diversidade, ou seja, os vencimentos se diferenciam em razão da carreira, do contrato de traba1ho, do cargo, do regime de trabalho, do nível e da classe, do tempo de serviço, das gratificações incorporadas, da titulação. Essa autora chama a atenção ainda para a diferença econômica regional existente no país, apresentando discrepâncias nas condições salariais entre diferentes redes públicas de educação, verificando-se até docentes com a mesma formação e titulação trabalhando em condições idênticas, sem, contudo, terem a isonomia salarial assegurada.

\section{CONSIDERAÇÕES}

Os resultados encontrados nesta pesquisa mostram que, no município de Belo Horizonte, somente em 2003 houve alterações significativas na construção da política pública de educação infantil, com a implantação do Programa Primeira Escola e a promulgação da lei n. 8.679/2003. Essas alterações foram sustentadas com a criação do cargo de educador infantil para o exercício da função docente nessa etapa da educação básica.

As tensões advindas da criação de uma carreira diferenciada para essa etapa da educação se fazem evidentes. Elas são enfatizadas especialmente na diferença salarial entre professoras e educadoras, sendo que estas últimas recebem atualmente por volta de $60 \%$ dos vencimentos das professoras, e que as atribuições da educadora infantil são semelhantes às das professoras que ainda atuam nessa etapa da educação básica nas escolas municipais.

Constatou-se que, no contexto atual da educação infantil em Belo Horizonte, as obrigações das professoras e das educadoras têm sido mais numerosas. Entretanto, percebe-se que, para a ampliação das atribuições e jornadas de trabalho, não se verifica a correspondência salarial e as condições necessárias à plena realização do trabalho docente. 
As professoras e as educadoras infantis relatam a existência de uma série de outras tarefas, além da interação com as crianças, tais como o planejamento e a elaboração de atividades, os registros de avaliação das crianças, a construção do PPP, a participação na gestão da escola, o trabalho coletivo e o trabalho com a comunidade. Observa-se também que muitas dessas atividades são realizadas fora do horário de trabalho remunerado.

Outros elementos que influenciam no trabalho, conforme apontado pelas participantes da pesquisa, dizem respeito à dificuldade de realizar um trabalho coletivo e ter de substituir a profissional que falta ao trabalho; à dificuldade em participar da formação continuada, em ter de lidar com as crianças com deficiência e em situação de vulnerabilidade social; ao cansaço físico em virtude da faixa etária das crianças; ao elevado número de crianças por adulto; às tensões e conflitos existentes entre professoras e educadoras, e à falta de apoio e reconhecimento das famílias, além da necessidade de terem de "dobrar" ou exercer outras atividades para complementar a renda.

Em relação à questão central sobre a qual se procurou refletir nesta pesquisa, as análises desenvolvidas aqui, embora não conclusivas, demonstram que se opera um processo de intensificação e precarização nas condições de trabalho das profissionais docentes da educação infantil da $\mathrm{RME} / \mathrm{BH}$, em virtude da criação do cargo de educador infantil e do salário a ele relativo, bem como da ampliação das áreas de atuação das docentes.

\section{REFERÊNCIAS}

Antunes, Ricardo. Os sentidos do trabalho: ensaio sobre a afirmação e a negação do trabalho. São Paulo: Boitempo, 1999.

Apple, Michael Whitman. Relações de classe e de gênero e modificações no processo do trabalho docente. Tradução Tomaz Tadeu da Silva. Cadernos de Pesquisa, São Paulo, n. 60, p. 3-14, fev. 1987.

Belo Horizonte (Município). Lei n. 7.235, de 27 de dezembro de 1996. Dispõe sobre o quadro especial da Secretaria Municipal de Educação, institui o plano de carreira dos servidores da educação da Prefeitura Municipal de Belo Horizonte, estabelece a respectiva tabela de vencimentos e dá outras providências. Diário Oficial do Município, Belo Horizonte, 1996. p. 1-6.

. Conselho Municipal de Educação. Resolução CME/BH n. 1/2000, de 13 de novembro de 2000. Estabelece as normas para a educação infantil no sistema municipal de ensino. Diário Oficial do Município, Belo Horizonte, 2000. p. 15-17.

Lei n. 8.679, de 11 de novembro de 2003. Cria as unidades municipais de educação infantil e o cargo de educador infantil, altera as leis n. 7.235/96 e 7.577/98 e dá outras providências. Diário Oficial do Município, Belo Horizonte, 2003. p. 2.

. Secretaria Municipal de Educação. Estruturação do trabalho escolar na RME/BH: a organização do trabalho coletivo por ciclos de formação. Belo Horizonte: Secretaria Municipal de Educação, 2006. 
. Edital 2/2008. Concurso público para provimento de cargos públicos efetivos de professor municipal, educador infantil, auxiliar de biblioteca escolar e auxiliar de secretaria escolar da carreira dos servidores da educação, e para o cargo público efetivo de analista de políticas públicas da carreira dos servidores da área da administração geral do quadro geral de pessoal da administração direta do Poder Executivo do município de Belo Horizonte. Diário Oficial do Município, Belo Horizonte, 2008.

Brasil. Constituição. Constituição da República Federativa do Brasil, 1988. Brasília: Senado Federal, Centro Gráfico, 1988.

Lei n. 9.394, de 20 de dezembro de 1996. Estabelece as Diretrizes e Bases da Educação Nacional. Diário Oficial da União, República Federativa do Brasil, Brasília, DF, 23 dez. 1996.

Braverman, Harry. Trabalho e capital monopolista: a degradação do trabalho no século XX. Rio de Janeiro: Guanabara, 1987.

CAmpos, Maria Malta. Educar e cuidar: questões sobre o perfil do profissional de educação infantil. Por uma política de formação do profissional de educação infantil. Brasília: MEC/SEF/DPE/COEDI, 1994. p. 32-42.

Castel, Robert. As metamorfoses da questão social: uma crônica do salário. Petrópolis: Vozes, 1998.

Cerisara, Ana Beatriz. Professoras de educação infantil: entre o feminino e o profissional. São Paulo: Cortez, 2002. (Coleção Questões da Nossa Época, v. 98).

DAL Rosso, Sadi. Jornada de trabalho: duração e intensidade. Ciência e cultura: temas e tendências. Ciência e Cultura, Sociedade Brasileira para o Progresso da Ciência (SBPC), São Paulo, v. 58, n. 4, p. 31-34, out./dez. 2006.

Dalben, Angela Imaculada Loureiro de Freitas et al. (Coords.). Educação infantil: o desafio da oferta pública. Belo Horizonte: UFMG /FaE/GAME, 2002.

Duarte, Adriana Maria Cancella. Regulação educacional e a complexidade do trabalho docente: formulações conceituais. 2008. Relatório Técnico de Pesquisa - Universidade Federal de Minas Gerais, Faculdade de Educação, Departamento de Administração Escolar, Belo Horizonte, 2008.

Dulci, Luiz. Por uma nova estratégia. Teoria e debate: diretório regional do PT/SP, São Paulo, Editora Fundação Perseu Abramo, n. 34, mar./maio 1997.

Kuenzer, Acácia Zeneida; Caldas, Andréa do Rocio. Trabalho docente: comprometimento e desistência. In: Simpósio Trabalho e Educação, 4., 2007. Belo Horizonte. Anais... Belo Horizonte: UFMG /FaE /NETE, ago. 2007.1 CD-ROM.

MArx, Karl. O capital: crítica da economia política. São Paulo: Abril Cultural, 1983.

Oliveira, Dalila Andrade. Mudanças na organização e na gestão do trabalho na escola. In: ___ _ Rosar, Maria de Fátima Félix (Orgs.). Politica e gestão da educação. Belo Horizonte: Autêntica, 2002. p. 125-143.

. Regulação educativa na América Latina: repercussões sobre a identidade dos trabalhadores docentes. Educação em Revista, Belo Horizonte, UFMG, n. 44, p. 209-227, dez. 2006. 
- Política educacional e a re-estruturação do trabalho docente: reflexões sobre o contexto latino-americano. Educação E̋ Sociedade, Campinas, CEDES, v. 28, n. 99, p. 355-375, maio/ago. 2007.

A educação básica na Lei de Diretrizes e Bases da Educação Nacional: breve balanço sobre a organização escolar e o trabalho docente. In: SouzA, João Valdir Alves de (Org.). Formação de professores para a educação básica: 10 anos de LDB. Belo Horizonte: Autêntica, 2008.p. 97-112.

Peduzzi, Marina; Schraiber, Lília Blima. Processo de trabalho em saúde. In: Pereira, Isabel Brasil; Lıma, Julio César França (Orgs.). Dicionário da educação profissional em saúde. Rio de Janeiro: Escola Politécnica de Saúde Joaquim Venâncio/Observatório dos Técnicos em Saúde, Fiocruz, 2006.

Rosemberg, Fúlvia. Avaliação de programas, indicadores e projetos em educação infantil. Revista Brasileira de Educação, Rio de Janeiro, ANPEd; Campinas, Autores Associados, n. 16, p. 19-26, jan./abr. 2001.

Sampaio, Maria das Mercês Ferreira; Marin, Alda Junqueira. Precarização do trabalho docente e seus efeitos sobre as práticas curriculares. Educação E Sociedade, Campinas, CEDES, v. 25, n. 89, p. 1.203-1.225, set./dez. 2004.

Santos, Oder José dos. Organização do processo de trabalho docente: uma análise crítica. Educação em Revista, Belo Horizonte, UFMG, n. 10, p. 26-30, dez. 1989.

Silva, Isabel de Oliveira. Profissionais da educação infantil: formação e construção de identidades. 2. ed. São Paulo: Cortez, 2003. (Coleção Questões da Nossa Época, v. 85). Silva, Maria Emília Pereira da. A metamorfose do trabalho docente no ensino superior: o impasse nas licenciaturas. 2007. Tese (Doutorado em Políticas Públicas e Formação Humana) - Universidade do Estado do Rio de Janeiro, Rio de Janeiro, 2007.

Souza, Aparecida Neri de. Professores de escolas técnicas: relações e condições de trabalho. In: Conferência Internacional Educação, Globalização e Cidadania: novas perspectivas da sociologia da educação. João Pessoa, Universidade Federal da Paraíba (UFPB) e a International Sociological Association (ISA), 2008. 1 CD-ROM. TARdif, Maurice; Lessard, Claude. O trabalho docente: elementos para uma teoria da docência como profissão de interações humanas. Petrópolis: Vozes, 2005.

VAsa pollo, Luciano. O trabalho atípico e a precariedade - elemento estratégico determinante do capital no paradigma pós-fordista. In: Antunes, Ricardo (Org.). Riqueza e miséria do trabalho no Brasil. São Paulo: Boitempo, 2006.

Vieira, Lívia Maria Fraga. Educação infantil no município de Belo Horizonte: histórico e situação atual. Belo Horizonte, 1998. (mimeo.).

\section{SOBRE AS AUTORAS}

Mércia de Figueiredo Noronha Pinto é doutoranda em educação pela Universidade Federal de Minas Gerais (UFMG).

E-mail: mercia.noronha@terra.com.br 
Adriana Maria Cancella Duarte é doutora em educação pela Universidade Federal de Minas Gerais (UFMG). Professora da mesma instituição. E-mail: driduarte58@gmail.com

Lívia Maria Fraga Vieira é doutora em sociologia da educação pela Universidade René Descartes. Professora da Universidade Federal de Minas Gerais (UFMG).

E-mail: liviafraga@globo.com 


\section{MÉRCIA DE FIGUEIREDO NORONHA PINTO, ADRIANA MARIA CANCELLA DUARTE E LIVIAA MARIA FRAGA VIEIRA}

O trabalho docente na educação infantil pública em Belo Horizonte

Este artigo resulta de uma pesquisa empírica sobre o trabalho docente na rede pública de educação infantil do município de Belo Horizonte. O marco dessa 
investigação é a implantação do Programa Primeira Escola, com a promulgação da lei n. 8.679/2003, que criou as Unidades Municipais de Educação Infantil (UMEIs). A partir dessa lei, Belo Horizonte deu início ao atendimento público às crianças com idade até 3 anos, ampliou as vagas para crianças na faixa etária de 4 a 5 anos, e criou o cargo de educador infantil, por meio de concurso público, para o exercício da função docente nessa etapa da educação básica. Os resultados mostram, entre outros aspectos, que a expansão da educação infantil pública no município de Belo Horizonte foi viabilizada mediante a criação de um cargo específico e com um salário inferior ao dos professores que atuam nas outras etapas da educação básica.

Palavras-chave: trabalho docente; educação infantil; política educacional; Rede Municipal de Educação de Belo Horizonte.

\section{Teachers' work in public early childhood education in Belo Horizonte}

This article results from an empirical study on teachers' work in public early childhood education in Belo Horizonte city. The landmark of this research is the implementation of the First School Program with the promulgation of law n. 8.679/2003, which created the Municipal Units of Early Childhood Education. With this law, Belo Horizonte began the service for children aged up to three years, expanded places for children aged four to five years and created the position of early childhood educator through public tender for the exercise of the teaching function at this stage of basic education. Among other aspects, results show that the expansion of public early childhood education in Belo Horizonte city was made possible by creating a specific position and paying a lower salary than that of the teachers who work in other levels of basic education.

Keywords: teachers' work; early childhood education; educational policy; Belo Horizonte's Municipal Education System.

\section{El trabajo docente en la educación infantil pública de Belo Horizonte}

Este articulo tiene origen en una investigación empirica sobre el trabajo docente en la red pública de educación infantil del municipio de Belo Horizonte. La investigación tiene lugar en el marco de la implementación del Programa "Primera Escuela" que, con la promulgación de la ley 8.679/2003, permitió crear las Unidades Municipales de Educación Infantil. A partir de ello se inicia, en Belo Horizonte, la atención pública de niños de hasta tres años de edad, se amplian las plazas para niños entre cuatro y cinco años, y se crea además, el oficio de educador infantil, por medio de concurso público, para el ejercicio de funciones docentes en esta etapa de la educación básica. Los resultados demuestran, entre otros aspectos, que la extensión de la educación infantil pública en el municipio de Belo Horizonte se hizo viable mediante la creación de un oficio especifico, que se paga con un sueldo inferior al de los profesores que trabajan en otras etapas o niveles de la educación básica.

Palabras clave: trabajo docente; educación infantil; politica educacional; Red Municipal de Educación de Belo Horizonte. 